\title{
AVALIAÇÃO MICROBIOLÓGICA DA CARNE-DE-SOL ELABORADA COM BAIXOS TEORES DE CLORETO DE SÓDIO ${ }^{1}$
}

\author{
Elizabete Lourenço da COSTA ${ }^{2}$, João Andrade SILVA ${ }^{3, *}$
}

\begin{abstract}
RESUMO
Foram analisadas 96 amostras de carne-de-sol, das quais 48 foram coletadas em estabelecimentos inspecionados e $48 \mathrm{em}$ estabelecimentos não-inspecionados. Com o objetivo de avaliar as condições higiênico-sanitárias desse produto, durante o processamento e a comercialização, pesquisou-se a incidência de bactérias mesófilas, bolores e leveduras, Staphylococcus aureus, coliformes fecais e Escherichia coli. Foram analisados ainda, alguns parâmetros físico-químicos como atividade de água e teor de cloreto de sódio. Nos dois grupos os resultados obtidos nas análises microbiológicas foram bastante elevados. Nas amostras provenientes de estabelecimentos inspecionados as médias da contagem total de bactérias mesófilas, bolores e leveduras, Staphylococcus spp e coliformes fecais foram 6,2Log UFC/g, 3,8Log UFC/g, 7,4Log UFC/g e 1,3Log NMP/g, respectivamente, e, nas comercializadas sem inspeção foram 7,4Log UFC/g, 4,4Log UFC/g, 6,8Log UFC/g e 2,6Log NMP/g, respectivamente. Esses resultados sugerem que houve falhas tanto no processamento como na manipulação desses produtos, sendo que a contaminação fecal foi bem mais elevada nas amostras coletadas nos estabelecimentos sem inspeção. A variação dos teores de cloreto de sódio e atividade de água das amostras indicou falta de padronização de qualidade da carne-de-sol, havendo a necessidade de se estabelecer parâmetros legais tanto microbiológicos como físico-químicos, capazes de oferecer ao consumidor um alimento seguro.
\end{abstract}

Palavras-chave: carne-de-sol; microbiologia; atividade de água; vida-de-prateleira.

\section{SUMMARY}

MICROBIOLOGICAL EVALUATION OF SUN DRIED MEAT WITH LOW SODIUM CHLORIDE. A total of 96 samples of sun meat were analyzed, 48 of them were collected in inspected establishments and the other 48 in establishments without inspection. This work was developed in order to evaluate the hygienic-sanitary conditions of these products during their processing and marketing. The incidence of mesophilic bacterias, molds, yeasts, Staphylococcus aureus, fecal coliforms and Escherichia coli was investigated. Also, some physical-chemical parameters as water activity and sodium chloride were analyzed. In both groups the results obtained in microbial analysis were quite high. In the samples of the inspected establishments the averages of mesophylic counts bacterias, molds and yeasts, Staphylococcus spp and fecal coliforms were 6,2Log UFC/g, 3,8Log UFC/g, 7,4Log UFC/g and 1,34Log NMP/g respectively and, in the samples without inspection, the averages were 7,41Log UFC/g, 4,44Log UFC/g, 6,78Log UFC/g and 2,6Log $\mathrm{NMP} / \mathrm{g}$, respectively. The microbial results suggest errors in the processing and manipulation of both samples, and the fecal

\footnotetext{
${ }^{1}$ Recebido para publicação em 20/10/99. Aceito para publicação em 25/06/01. Este trabalho é parte da Dissertação de Mestrado do primeiro autor.

${ }^{2}$ Aluna do Curso de Pós-Graduação em Ciências da Nutrição FEA/UNICAMP

${ }^{3}$ Professor do Departamento de Nutrição UFPb CCS/DN - João Pessoa-Pb CEP 58051-900.

${ }^{*}$ A quem a correspondência deve ser enviada.
}

contamination was much higher in the samples collected in establishments without inspection. The variation of the sodium chloride content and water activity of the sample indicated lack of standardization during sun dried meat processing. There is the need tho establish microbiological and physical-chemical legal parameters capable of offering safe food to the consumer.

Keywords: meat; microbiology; water activity; shelf life.

\section{1 - INTRODUÇÃO}

A carne bovina curada representa cerca de $25 \%$ da produção de carnes produzidas pelos estabelecimentos sob inspeção federal no Brasil, sendo o principal produto, o charque [15]. A estatística apresentada não discrimina a produção da carne-de-sol, um produto amplamente consumido na região Nordeste, curada exclusivamente pela adição de relativamente baixa concentração de cloreto de sódio, em média $5,0 \%$ oscilando entre 2,9 e $11,9 \%$ [14, 20]. A variabilidade desses valores indica a falta de padronização do seu processamento, que consiste na utilização da salga seca e desidratação durante o empilhamento das mantas por algumas horas, podendo ser expostas ao sol, dependendo do fabricante. $O$ resultado é um produto semidesidratado com características sensoriais muito peculiares.

Esse produto surgiu como uma alternativa na preservação do excedente de produção da carne bovina, face as dificuldades encontradas para a sua conservação, pois devido ao baixo nível econômico da população, optava pelo processo de salga e desidratação, uma vez que às condições climáticas e a disponibilidade de sal marinho no Nordeste brasileiro são bastante favoráveis a essa prática [13]. A utilização desta técnica acabou popularizando a carne-de-sol, que continua sendo produzida em condições higiênico-sanitárias insatisfatórias, resultando em um produto com vida-de-prateleira entre 3 e 5 dias [17].

A microbiota da carne depende das condições nas quais os animais foram criados, abatidos e processados [18]. Por se tratar de um produto sem registro no Ministério da Agricultura, a carne-de-sol, atualmente comercializada, geralmente procede de abates clandestinos, o que pode aumentar o risco da incidência de gastroenterites alimentares. Um outro fator que pode ser determinante para as altas contagens de microrganismos encontradas nesse produto é o baixo teor de sal utilizado, suficiente apenas para reduzir a atividade de água para valores próximos a 0,96 , capazes de inibir o crescimento de Pseudomonas, mas oferecendo condições favoráveis para o desenvolvimento de bactérias Gram-positivas, como as pertencentes ao gênero Staphylococcus [20]. 
Esse gênero de bactérias é formado por organismos com características seletivas que o torna favorecido frente às outras bactérias, cresce e produz enterotoxina em baixos valores de atividade de água, [6]. São halotolerantes, crescem bem em até $15 \%$ de sal [11], podendo representar um perigo adicional, pela falta de microrganismos competidores [7]. Sua presença também pode ser utilizada como indicativo de condições inadequadas de manipulação.

Outros microrganismos de interesse na avaliação da qualidade da carne-de-sol são os coliformes, indicadores de contaminação fecal durante o abate e o processamento, indicando também a possível presença de microrganismos patogênicos [9].

A Portaria n 451 de 19 de setembro de 1997 do Ministério da Saúde [2] é omissa sobre as características microbiológicas da carne-de-sol. Considerando o grande volume desse produto, comercializado no Nordeste brasileiro, existe a necessidade da definição de critérios e padrões físico-químicos para sua elaboração, pois este produto parcialmente desidratado e semipreservado pela salga não pode se enquadrar no padrão existente para o charque e similares, porque sua vida-de-prateleira é muito curta quando comparada a estes produtos [10]. Portanto, esse trabalho teve como objetivo avaliar alguns parâmetros relativos à sua qualidade higiênico-sanitária.

\section{2 - MATERIAL E MÉTODOS}

\section{1 - Amostras}

Foi analisado um total de 96 amostras de carnede-sol, sendo 48 coletadas em supermercados e frigoríficos e 48 provenientes de estabelecimentos nãoinspecionados, tais como feiras livres, mercados públicos e outros estabelecimentos de pequeno porte. As amostras foram adequadamente acondicionadas e conduzidas ao Laboratório de Microbiologia de Alimentos (Departamento de Nutrição/CCS/UFPB), onde foram realizadas as análises microbiológicas. As análises de atividade de água e teor de cloretos foram realizadas no Laboratório de Tecnologia Química de Alimentos (Departamento de Tecnologia Química e de Alimentos/ CT/UFPB).

\section{2 - Análises microbiológicas}

Pesaram-se assepticamente $25 \mathrm{~g}$ de cada amostra que foram trituradas e diluídas em $225 \mathrm{~mL}$ de solução salina peptonada $0,1 \%$. A diluição obtida correspondeu a diluição $10^{-1}$ [19], a partir da qual foram obtidas as demais diluições decimais até $10^{-7}$.

Utilizando-se as técnicas recomendadas por VANDERZAN \& SPLITTSTOESSER [23], realizou-se a contagem total d bactérias mesófilas, bolores e leveduras, Staphylococ us aureus a determinação do número mais provável de coliformes fecais e Escherichia coli.

Contagem tctal de bactérias aeróbias mesófilas As diluições de cada amostra foram semeadas, em duplicata, utilizando-se a técnica em profundidade, empregando-se o meio "plate count agar" fundido. Após a solidificação do ágar, as placas foram incubadas a $37^{\circ} \mathrm{C}$ por 48 horas.

Contagem total de bolores e leveduras - Nessa determinação utilizou-se ágar batata dextrose acidificado com ácido tartárico a $1 \%$. As placas foram incubadas a $25^{\circ} \mathrm{C}$ por $96 \mathrm{~h}$.

Staphylococcus aureus - De cada diluição, foram transferidas alíquotas de $0,1 \mathrm{~mL}$ para a superfície do meio Baird Parker, semeado com o auxílio de uma alça de Drigalsky. Após a secagem, as placas foram incubadas a $37^{\circ} \mathrm{C}$ por $48 \mathrm{~h}$. As colônias típicas foram coradas pela técnica de coloração de Gram e submetidas aos testes de catalase, coagulase e DNAse.

Bactérias coliformes - Nessa análise utilizou-se a técnica de diluições decimais em triplicata, onde cada tubo com caldo lauril sulfato triptose continha tubos de fermentação invertidos, inoculou-se $1,0 \mathrm{~mL}$ de cada diluição da amostra e incubou-se por $48 \mathrm{~h}$ a $37^{\circ} \mathrm{C}$. A partir de cada tubo positivo foi transferida uma alçada, para tubos com caldo E.C. e incubados a $45,5^{\circ} \mathrm{C}$ por $24 \mathrm{~h}$ em banho-maria. Os tubos EC positivos foram semeados em ágar eosina azul de metileno e incubado por $24 \mathrm{~h}$ a $37^{\circ} \mathrm{C}$. As colônias típicas foram submetidas ao teste IMViC para a confirmação da presença de Escherichia coli.

\section{3 - Análises físico-químicas}

Teor de cloretos - Os cloretos foram determinados pelo método titulométrico, de acordo com a metodologia da AOAC [1].

Atividade de água - $\mathrm{A}$ atividade de água foi determinada por método direto, utilizado-se higrômetro Decagon, da marca Aqua Lab, modelo CX2, calibrado a $20^{\circ} \mathrm{C}$. Foram feitas três leituras por amostra [23].

\section{4 - Análises estatísticas}

A estatística descritiva e as diferenças entre as médias foram obtidas utilizando-se o Software Statistic for windows [21].

\section{3 - RESULTADOS E DISCUSSÃO}

\section{1 - Resultados das análises microbiológicas}

Pela ausência de padrões microbiológicos para a carne-de-sol na legislação brasileira foi tomado como parâmetro as especificações para carnes como charques e similares.

As médias dos resultados obtidos nas análises microbiológicas das amostras provenientes dos estabelecimentos sem inspeção foram mais elevadas do que as observadas nas amostras coletadas nos estabelecimentos inspecionados (Figuras 1 e 2). No entanto, a pesquisa do número mais provável de coliformes fecais apresentou diferença significativa $(p<0,05)$, sugerindo que em todos os locais de coleta das amostras, a car- 
ne-de-sol estava sendo manipulada inadequadamente.

FIGURA 1. Microrganismos pesquisados nas amostras de carne-de-sol coletadas em estabelecimentos inspecionados

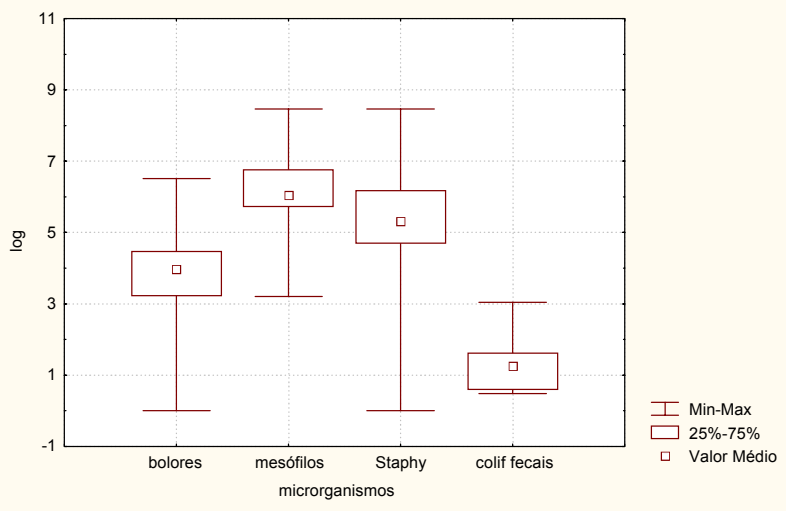

FIGURA 2. Microrganismos pesquisados nas amostras de carne-de-sol coletadas em estabelecimentos não-inspecionados

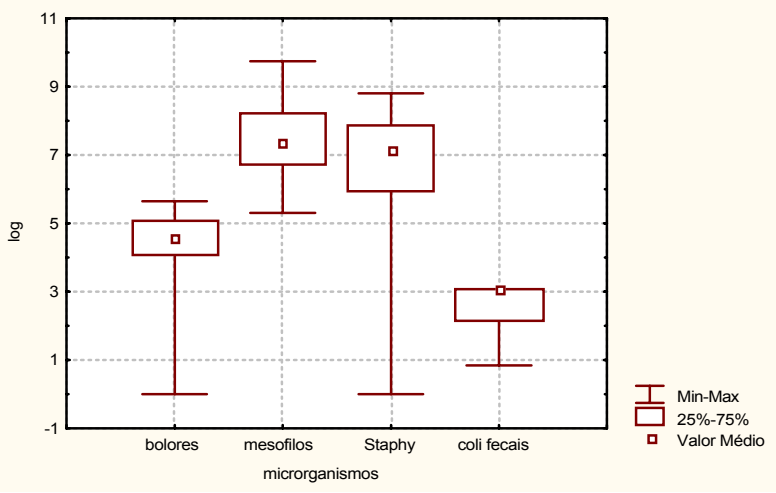

Nas amostras coletadas em estabelecimentos não inspecionados, verificou-se uma grande contaminação por microrganismos de origem fecal, ou seja, o número mais provável desse grupo de microrganismos foi superior a dois ciclos logarítmicos em $81,2 \%$ das amostras analisadas, limite máximo estabelecido pela Portaria n 451 de 19 de setembro de 1997 do Ministério da Saúde [2]. Nos estabelecimentos inspecionados, apenas $18,7 \%$ das amostras encontravam-se fora dessa especificação. Entretanto, mesmo nas amostras com pequena incidência de coliformes fecais verificou-se a presença de Escherichia coli em 56,3\% do total das amostras, já as provenientes dos estabelecimentos nãoinspecionados apresentaram o microrganismo em $66,7 \%$ delas. A presença de $E$. coli não é tolerada, mesmo em pequenas quantidades, visto que algumas cepas desse microrganismo são comprovadamente enterotoxigênicas e têm sido envolvidas em surtos de gastroenterites severas [3].

Resultados próximos aos obtidos neste trabalho foram encontrados por SILVA [20] que detectou a $E$. coli em $45,0 \%$ das amostras de carne-de-sol comercializadas em feiras livres.
A contagem total das bactérias mesófilas de um produto pode ser utilizada como indicativo do histórico da manipulação a que ele foi submetido, com reflexo na qualidade da matéria-prima empregada, bem como na vida-de-prateleira, do produto final [14]. As médias das contagens desse grupo de microrganismos nas amostras coletadas nos estabelecimentos inspecionados e sem inspeção foram 6,2 $\pm 1,09$ e 7,4 $\pm 1,02 \mathrm{Log}$ UFC/g, respectivamente. A legislação brasileira não especifica um limite para a contagem total de microrganismos em carnes e produtos derivados. No entanto, na bibliografia consultada, de um modo geral, produtos que apresentam contagens entre 5 e $6 \mathrm{Log}$ UFC/g são considerados como altamente contaminados, conseqüentemente, produtos cárneos com contagens acima desses valores são considerados impróprios para o consumo [5, 20], embora esses valores têm como referência a carne fresca. Entretanto para SHIMOKOMAKI et al [17], valores entre 5 e 10Log UFC/g devem ser considerados comuns para a carne-de-sol, em decorrência das condições higiênico-sanitárias deficientes durante a produção e armazenamento deste produto. JAY [7] também admite a adoção de patamares mais elevados com relação aos microrganismos da flora natural dos alimentos, pelo fato de competirem com microrganismos patogênicos, embora admita que carnes com contagens acima de 7Log UFC/g possam apresentar odores desagradáveis. Os resultados apresentados na Figura 2 mostram que cerca de $60,0 \%$ das amostras coletadas nos estabelecimentos não-inspecionados apresentavam contagens acima desse valor.

Nos dois grupos de amostras submetidos às análises foram detectadas elevadas contagens de Staphylococcus spp; nos estabelecimentos inspecionados a contagem média estava em torno de 5,29 $\pm 1,69$ e nos não-inspecionados $6,78 \pm 1,56 \mathrm{Log}$ UFC/g, sendo que para este grupo, mais de $50,0 \%$ das amostras apresentaram contagens superiores a $7 \mathrm{Log}$ UFC/g, (Figura 2). Foi detectada uma baixa freqüência de $S$. aureus nas amostras dos dois grupos, estando presente em $14,6 \%$ das amostras dos estabelecimentos inspecionados e em $10,4 \%$ das amostras dos não-inspecionados. Apesar da baixa incidência desse microrganismo, a média da contagem foi superior a $5 \mathrm{Log}$ UFC/g, representando o risco da presença da enterotoxina suficiente para desencadear a intoxicação alimentar [16].

Durante o processamento da carne-de-sol é comum a utilização de utensílios de madeira que absorvem umidade e matéria orgânica, transformado-se em ambientes ideais para a proliferação dos bolores e leveduras. Além da espoliação da carne os fungos podem sintetizar substâncias tóxicas para os seres humanos [24]. A Legislação Brasileira também não regulamenta níveis de bolores e leveduras para produtos cárneos, mas analisando a microbiota inicial da carne bovina SILVA [19] obteve contagens na ordem de 1,66Log UFC/g. Nas Figuras 1 e 2 observa-se que as contagens médias estavam em torno de $3,8 \pm 1,02$ para os estabelecimentos inspecionados e 4,44 $\pm 0,95$ para as amostras dos estabelecimentos não-inspecionados, valores coerentes 
com os encontrados por VALADARES et al [22] ao analisar carnes de qualidade inferior utilizadas como matéria-prima para embutidos $(4,39 \mathrm{Log} \mathrm{UFC} / \mathrm{g})$.

\section{2 - Resultados da determinação físico-química}

A atividade de água de um alimento é a medida mais acurada para se determinar a habilidade do crescimento microbiano [12], que pode ser reduzida tanto pela desidratação como pela adição de solutos [6]. As Figuras 3 e 4 mostram o comportamento da atividade de água nas amostras dos dois grupos em função da concentração de cloreto de sódio, apresentando uma correlação de $-0,49(p<0,05)$, valores médios de atividade de água de 0,94 $\pm 0,02$, com uma amplitude de 0,89 a 0,97 , para as amostras coletadas nos estabelecimentos inspecionados. A mesma média foi obtida para as amostras coletadas nos estabelecimentos sem inspeção, com uma amplitude de 0,88 e 0,98 e a correlação encontrada entre os parâmetros cloreto de sódio e atividade de água foi um pouco mais elevada, qual seja, $r=-0,69(p<0,05)$.

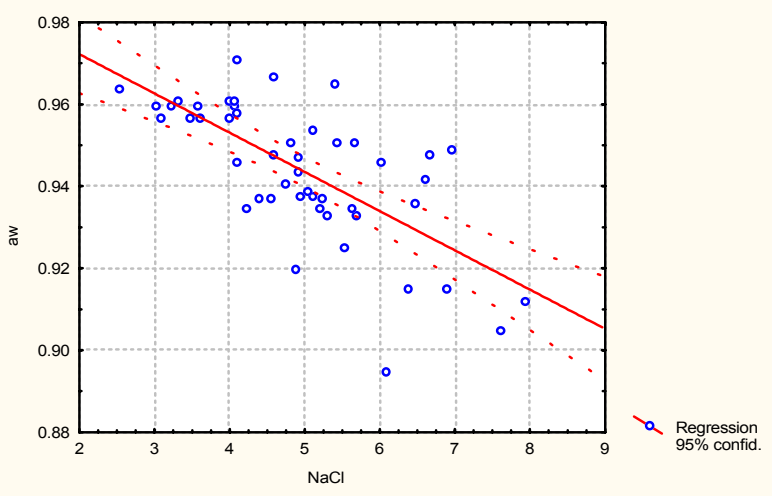

FIGURA 3. Correlação entre a aw e o $\mathrm{NaCl}$ na carne-de-sol comercializada em estabelecimentos inspecionados $r=-0,49$

Carnes processadas com atividade de água entre 0,97 e 0,98 têm sua vida-de-prateleira reduzida, uma vez que esses valores correspondem a faixa ótima de crescimento de bactérias deterioradoras como as Pseudomonas fluorescens, principalmente nos produtos elaborados com baixo teor de cloreto de sódio. $\mathrm{O}$ crescimento desses microrganismos pode provocar alterações na coloração, odores desagradáveis e limosidade superficial [8]. Além disso DELLAPINA et al [4] observaram a sobrevivência de Salmonella, Listeria monocitogenes e Staphylococcus aureus em carnes prépreparadas, com atividade de água dentro da faixa encontrada na carne-de-sol $(0,97 ; 0,94$ e 0,90$)$, sendo o microrganismo mais sensível a Salmonella, quando a atividade de água foi de 0,90 . Portanto faz-se necessário a adoção de técnicas de preservação mais efetivas, que minimizem esse risco, já que se trata de um alimento muito suscetível a contaminações em todas as etapas de seu processamento.

Pelos resultados obtidos nessa pesquisa, os dois grupos de amostras apresentaram contaminações bastante elevadas, superiores aos valores normalmente admitidos na bibliografia consultada. Constatou-se que as amostras comercializadas nos estabelecimentos sem inspeção apresentaram uma maior extensão da contaminação por microrganismos de origem fecal, o que pode indicar a presença de bactérias patogênicas. Os dois grupos de amostras também apresentaram uma elevada incidência das bactérias do gênero Staphylococcus, o que sugere hábitos higiênicos incorretos durante o processamento. A presença do $S$. aureus foi detectada em baixa frequência, mas em quantidades suficientes para formar enterotoxinas.

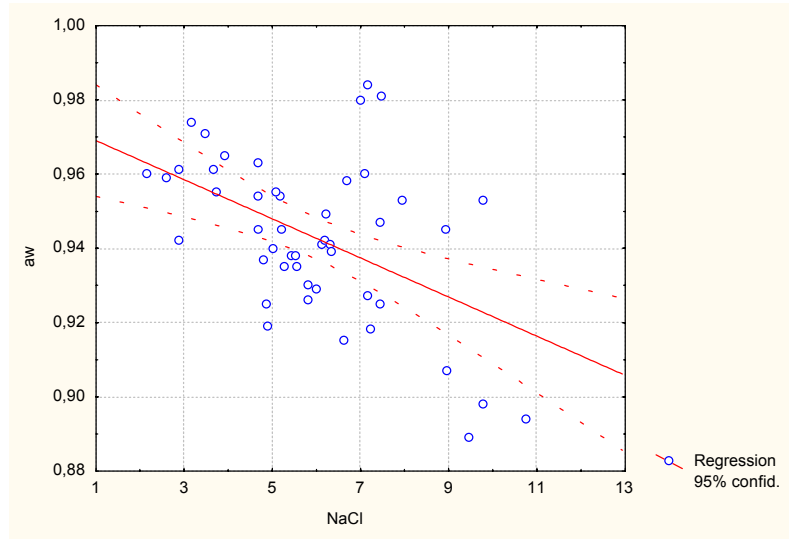

FIGURA 4. Correlação entre a aw e o $\mathrm{NaCl}$ das amostras de carne-de-sol comercializadas em estabelecimentos sem inspeção $r=-0,69$

\section{4 - CONCLUSÕES}

Há necessidade de uma padronização em etapas importantes do processamento da carne-de-sol, como o período de secagem e o teor de cloreto de sódio e ainda a adição de conservantes que não alterem as características sensoriais visando a obtenção de valores de atividade de água mais baixa na tentativa de oferecer produto seguro ao consumidor.

\section{5 - REFERÊNCIAS BIBLIOGRÁFICAS}

[1] A.O.A.C. OFFICIAL METHODS OF ANALYSIS OF THE ASSOCIATION OF ANALYTICAL CHEMISTS. 14 ed. Alington: George Banta, Virginia, 1984.

[2] BRASIL, Ministério da Agricultura. Portaria n. ${ }^{\circ} 451$ de 19 de setembro de 1997, Dispõe sobre as normas e padrões de controle microbiológico para alimentos. Diário Oficial [da República Federativa do Brasil], Brasília, 19 set. 1997.

[3] CHAPMAN, P. A. Verocytotoxin - producing Escherichia coli O157 infections. Reviewing the background, epidemiology, methods of detection and prospects for control. British Food Journal, v. 97, n. 10, p. 29-31, 1995.

[4] DELLAPINA G.; BARBUTI, S.; CAMPANINI, M.; DALL'AGLIO G. Sopravvivenza e inattivazione di microrganismi patogeni in semilavorati di carne a ridotta attività dell'acqua. Industria Conserve, v. 71, p. 299-305, 1996.

[5] FUNG, D. Y. C., KASTNER, C. L., HUNT, M. C., DIKEMAN, M. E., KROPK, D. Mesophilic and psychrotrophyc bacteria population on hot-boned and conventionally processed beef. Journal of Food Protection, v. 43, n. 7, p. 547-550, 1980. 
[6] ICMSF - International Commission on Microbiological Specifications for Foods. Ecologia microbiana de los alimentos - Fatores que afectan la supervivencia de los microorganismos en los alimentos. Zaragoza, Acribia, 1980, 332p. v. 1.

[7] JAY, J. M. Microorganisms in fresh ground meats: the relative safety of products with low versus high numbers. Meat Science, v. 43S, p. 59-66, 1996.

[8] LEBERT, I.; BEGOT, C.; LEBERT, A. Growth of Pseudomonas fluorescens and Pseudomonas fragi in a meat medium as affected by $\mathrm{pH}(5,8-7,0)$ water activity $(0,97-1,00)$ and temperature $\left(7-25^{\circ} \mathrm{C}\right)$. International Jounal of Food Microbiology, v. 39, n. 1/2, p. 53-60, 1998.

[9] LEITÃO, M. F. F. Microbiologia de Alimentos: In ROITMAN, I., TRAVASSOS, L. R., AZEVEDO, J. L. Tratado de microbiologia. São Paulo: Manole, p. 3-80, 1988

[10] LIRA, G. M., SHIMOKOMAKI, M. Parâmetros de qualidade da carne-de-sol e dos charques Higiene Alimentar, v. 12, n. 58, p. 33-35, 1998.

[11] LOUCH, H., ECK, M. L., MILLER, K. J. Osmoadaptation by Staphylococcus aureus: Analysis of several strains linked to food poisonig outbreaks. Journal of Food Protection, v. 60, n. 2, p. 139-143, 1997.

[12] MBUGUA, S. K., KARURI, E. G. Preservation of beef using bacteriostatic chemicals and solar drying. Food and Nutrition Bulletin, v. 15, n. 3, p. 262-268, 1994.

[13] NÓBREGA, D. M. \& SHINEIDER, I. S. Contribuição ao estudo da carne de sol visando melhorar sua conservação. Higiene Alimentar, v. 2, n. 3, p. 150-154, 1983.

[14] NÓBREGA, D. M. Contribuição ao estudo da carne-de-sol visando melhorar sua conservação. Campinas, 1982. 81p. (Mestre em Tecnologia de Alimentos) Faculdade de Engenharia de Alimentos - Universidade Estadual de Campinas (UNICAMP).
[15] PARDI, M. C., SANTOS, I. F. S., SOUZA, E. R. Ciência Higiene e Tecnologia da Carne. Goiânia: Editora UFG, v. 2, 1996, 1110p.

[16] PEARSON, A. M., DUTSON, T. R. Advances in meat research. Connecticut: AVI. 1986, 436p.

[17] SHIMOKOMAKI, M., FRANCO, B. D. G. M., CARVALHO JR, B. C. Charque e produtos afins: tecnologia e conservação - uma revisão. Boletim SBCTA, v. 21, n. 1, p. 25-35, 1987.

[18] SILVA, J. A. Microbiologia da carcaça bovina: Uma revisão. Revista Nacional da Carne, v. 24, n. 10, p. 62-87, 1997.

[19] SILVA, J. A. Extensão da vida-de-prateleira da carne bovina pela utilização de sanitizantes físicos e químicos. Campinas, 1995. 119p. (Doutor em Engenharia de Alimentos) Faculdade de Engenharia de Alimentos, Universidade Estadual de Campinas (UNICAMP).

[20] SILVA, M. C. D. Incidência de Staphylococcus aureus enterotoxigênicos e coliformes fecais em carne de sol comercializada na cidade do Recife- PE. Recife, 1991, 77p. (Mestre em Ciência de Alimentos) Departamento de Nutrição, Universidade Federal de Pernambuco (UFPE).

[21] STATSOFT, Inc. (1995). Statistic for windows (Computer program manual). Tulsa, StatSoft, Inc., 2325 East $13^{\text {th }}$ Street, Tulsa, OK, 74104.

[22] VALLADARES, C., VILLAMIL, R., GUERRA, M. A., LÓPEZ, $R$. Calidad higienica de emulsiones para productos carnicos. Alimentaria, v. 35, n. 282, p. 55-57.

[23] VANDERZANT, C., SPLITTSTOESSER, D. F. Compendium of methods for the microbiological examination of foods, $3^{\text {th }}$ ed., Washington, APHA, 1992, 1219p.

[24] VELD, J. H. J. H., MULDER, R. W. A. W., SNIJDERS, J. M. A. Impact of animal husbandry and slaughter technologies on microbial contamination of meat: monitoring and control. Meat Science, v. 36, p. 123-154, 1994. 